\title{
ORIGINAL ARTICLE \\ Posttraumatic growth in people with traumatic long-term spinal cord injury: predictive role of basic hope and coping
}

\author{
S Byra
}

Study design: Participants with spinal cord injury (SCI) sustained at least 15 years before the study completed questionnaires measuring posttraumatic growth (PTG), basic hope and coping strategies.

Objectives: To determine contribution of basic hope and coping strategies to accounting for PTG variability in participants with traumatic long-term SCl.

Setting: Polish rehabilitation centres, foundations and associations implementing social inclusion and professional activation programmes. Participants were enrolled based on their medical history by trained rehabilitation specialists and psychologists.

Methods: The set of questionnaires included the following: The Post-traumatic Growth Inventory; The Coping Orientations to Problems Experienced (COPE); and Basic Hope Inventory.

Results: A study of 169 individuals with paraplegia in the range of PTG showed the highest degree of positive changes in appreciation of life $(A L)$ and the lowest in self-perception. Regression analysis showed that coping strategies such as religion (REL), focus on the problem, humour, alcohol/drug use ideation and basic hope jointly account for $60 \%$ of variance of PTG. The highest contribution to accounting for this variability had REL. Also, it was found that coping strategies and basic hope allow to predict variance of individual growth aspects. Age at trauma exposure positively correlated with changes in AL and spiritual change. No significant relationship between growth and age of participants was confirmed.

Conclusion: PTG occurring in people with long-term traumatic SCl is primarily manifested in increased AL. Specific coping strategies and basic hope have a significant role in fostering positive changes.

Spinal Cord (2016) 54, 478-482; doi:10.1038/sc.2015.177; published online 8 December 2015

\section{INTRODUCTION}

The onset of a spinal cord injury (SCI) leads to radical changes in life and involves various physical, psychological and social changes. ${ }^{1}$ Psychopathological consequences have been widely investigated. Trauma outcomes in the form of positive changes (such as posttraumatic growth (PTG), benefit finding) have started to be explored only recently. They were found to occur in individuals after SCI. ${ }^{1-3}$ Their nature, however, just as determining factors, has not been properly explained. Positive change following a traumatic event such as SCI is conceptualised, among others, as PTG. Tedeschi and Calhoun ${ }^{4}$ find it to be the result of successful coping with trauma outcomes. SCI classified as radical life-altering seismic event may significantly impact occurrence of PTG. However, it is not the event itself that contributes to emergence of this phenomenon. As shown in the study, it occurs in some individuals, it has different degrees and affects life areas to various extent. ${ }^{3}$ This suggests that there must emerge some specific conditions and factors producing such positive change in a person with SCI. Growth determinants in people with SCI have not been sufficiently identified.

The onset of a SCI considerably challenges adaptive beliefs about fair and ordered world, sense of control and positive self-concept. PTG is a manifestation of restructuring previous patterns of thinking about the world and ways of human functioning in it. Basic hope is therefore of high significance in this context. It is construed as generalised and collected beliefs of an individual about arrangement, senses of the world and its favourable approach to people. Basic hope is regarded as a relatively stable personality constituent enabling an individual to provide a constructive response to new situations and circumstances that led to collapse of their former reality. ${ }^{5}$ Among others, predictive functions of basic hope in determining the degree of adaptation to an irreversible loss, mobilising an individual to develop and look for new life interests, ${ }^{5,6}$ as well as its significance for PTG in people after an accident leading to loss of motor functions were confirmed. ${ }^{6}$ Higher level of hope was related to higher PTG in those participants whose accident took place at least 2 years before the study. These findings may therefore suggest that the period following trauma may be important for revealing adaptive functions of basic hope. Predictive role of basic hope in determining growth in people with long-term disability was not established however.

Another important component of adaptation following development of permanent injuries, reconstituting disturbed balance between personal possibilities and expectations of the environment, is coping. Adaptive and non-adaptive coping was analysed in connection with favourable and undesirable SCI outcomes. $^{7-9}$ PTG was investigated to a considerably smaller extent. In the study by Elfström et al., ${ }^{10}$ acceptance coping positively correlated with personal growth after trauma. Individuals displaying high A reported significantly higher personal growth than people with poorly developed

Faculty of Pedagogy and Psychology, Institute of Pedagogy, Maria Curie-Skłodowska University, Lublin, Poland

Correspondence: Professor S Byra, Faculty of Pedagogy and Psychology, Institute of Pedagogy, Maria Curie-Skłodowska University, ul. Narutowicza 12, Lublin 20-004, Poland. E-mail: stanislawa.byra@poczta.umcs.lublin.pl

Received 6 February 2015; revised 11 August 2015; accepted 4 September 2015; published online 8 December 2015 
strategy of coping with trauma outcomes through acceptance. ${ }^{11}$ Significance of coping for PTG in people after SCI was determined in a longitudinal study. Among others, it was proved that coping strategy (mainly acceptance coping) applied 12 weeks after trauma accounts for increased growth after 2 years ${ }^{12}$ and after 10 years (mental disengagement and active coping). ${ }^{1}$

The objective of this study is to determine the contribution of basic hope and coping strategies to accounting for PTG in individuals with traumatic long-term SCI.

\section{MATERIALS AND METHODS}

\section{Participants}

Study participants were 169 individuals with paraplegia. Selection criteria were as follows: (1) Injury was developed at least 15 years before the study; and (2) Traumatic injury. Individuals with diagnosed cognitive impairments or communication disorders (based on medical record and knowledge of rehabilitation specialists and psychologists) were excluded from the study. Participant characteristics are presented in Table 1.

\section{Materials}

Data were completed using the following inventories:

Polish version of The Post-traumatic Growth Inventory. Confirmatory factor analysis performed by $\mathrm{N}$ Ogińska-Bulik and Z Juczyński provided grounds for selecting a four-factor structure: (1) changes in self-perception (CHSP) (Cronbach's $\alpha=0.87$ ), (2) changes in relations to others (Cronbach's $\alpha=0.85$ ), (3) appreciation of life (AL) (Cronbach's $\alpha=0.73$ ), and (4) spiritual changes (Cronbach's $\alpha=0.63) .{ }^{13}$ Polish adaptation of the tool was prepared, including translation and retranslation of the items. Satisfactory indicators of reliability and validity of the Polish version of The Post-traumatic Growth Inventory were found.

Polish version of The Coping Orientations to Problems Experienced developed by $\mathrm{K}$ Wrześniewski. It is a 60 -item scale determining frequency of applying the following strategies: focus on the problem (PROB), denial, focus on/venting of emotions, seeking emotional support, acceptance, religion (REL), humour (HUM), and alcohol/drug use ideation (ALK). Polish version of the

\section{Table 1 Participant characteristics}

\begin{tabular}{lc}
\hline Characteristics & Descriptor \\
\hline Sex, $n$ (\%) & \\
$\quad$ Men & $129(76.33)$ \\
Women & $40(23.67)$ \\
& \\
Place of residence, $n$ (\%) & \\
$\quad$ City & $147(86.98)$ \\
Rural areas & $22(13.02)$ \\
& \\
Marital status, $n$ (\%) & \\
Married & $66(39.05)$ \\
Single & $58(34.32)$ \\
Divorced & $15(8.87)$ \\
Separated & $17(10.06)$ \\
Widowed & $13(7.69)$ \\
& \\
Education, $n$ (\%) & \\
Primary & \\
Vocational & $24(14.20)$ \\
Secondary & $38(22.48)$ \\
Higher, incomplete & $73(43.19)$ \\
Higher & $11(6.51)$ \\
Age, mean (s.d.) & $23(13.61)$ \\
Age at trauma, mean (s.d.) & $49.44(13.79)$ \\
& $26.93(15.13)$ \\
\hline
\end{tabular}

inventory contains satisfactory psychometric indicators; reliability coefficients of individual subscales range from 0.62 to 0.93 Cronbach's $\alpha$. Correlation coefficients are also satisfactory (ranging from 0.60 to 0.80 for different scales)..$^{14}$

Basic Hope Inventory (BHI) by Trzebiński and Zięba contains 12 statements evaluated by respondents according to a five-item scale. It allows to determine the general level of basic hope manifested in personal beliefs about the world, its arrangement, senses and positive nature. Psychometric properties of the instrument are satisfactory: Cronbach's $\alpha-0.70$ and Pearson's $r=0.62 .{ }^{15}$

\section{Procedures}

Data included in the study were collected among participants of social inclusion or professional activation projects implemented in a number of cities by foundations and associations acting for people with mobility disabilities. Inventories were distributed by trained psychologists and rehabilitation specialists working for the aforesaid institutions. Encoded data were stored in accordance with valid personal data protection regulations.

\section{Data analysis}

Data were analysed using Statistica 7.0 suite (Statsoft Poland, Cracow, Poland). First, descriptive statistics were prepared for examined variables: PTG, coping strategies, and basic hope. Next correlation analysis was performed to determine the relationship between PTG, basic hope and coping strategies (Pearson's correlation coefficient). Finally, standard stepwise regression analysis was conducted to check contribution of variables found as independent variables: basic hope and coping strategies, in accounting for the dependent variable of PTG. Scatter plots and collinearity statistics were first verified to meet the linearity and normality assumptions.

\section{RESULTS}

\section{Incidence of PTG, coping strategies and basic hope}

Table 2 presents descriptive statistics for PTG (general result and specific aspects), coping strategies and basic hope. To compare the levels of individual aspects of PTG across participants, total score obtained by each participant was divided by the number of items.

Relationships between age, age at trauma exposure, basic hope, coping strategies and PTG

PTG showed no significant relationships with age of participants: total PTG $(r=-0.12)$, CHSP $(r=-0.15)$, changes in relations to others $(r=-0.17), \mathrm{AL}(r=0.12)$ and spiritual changes $(r=-0.06)$. Age at trauma exposure was significantly and positively correlated with only two PTG aspects: AL $(r=0.22)$ and spiritual changes $(r=0.17)$; and the strength of this correlation is weak. Table 3 presents correlation coefficients between PTG, coping and basic hope. Only coping through denial and venting of emotions negatively correlates with the general PTG result. In contrast, coping strategies such as PROB, acceptance and REL positively correlated with all aspects of PTG and the general result. Also, basic hope positively correlated with all growth aspects and the general result.

Next standard stepwise regression analysis was performed to find out whether basic hope-and what coping strategies — has a predictive role for PTG. Table 4 contains the results of the multiple regression for the general PTG score. Combination of five independent variables (coping strategies: REL, ALK, HUM, PROB and basic hope) accounted for $60 \%$ of the variance of PTG levels in this sample. Of the five variables, REL made the largest unique contribution.

Analyses intended to determine the impact of coping and basic hope on variability of individual growth aspects were also performed. For CHSP, predictive role of coping (REL- $\beta=0.45, R^{2}=0,26$; PROB $-\beta=42, R^{2}=0.08$; focus on emotions $-\beta=0.24, R^{2}=0.07$; ALK $-\beta=-0.31, \quad R^{2}=0.02 ; \quad$ HUM- $\beta=0.38, \quad R^{2}=0.04 ; \quad$ seeking emotional support $\left.-\beta=-0.21, R^{2}=0.03\right)$ and basic hope $(\beta=0.37$; 
Table 2 Descriptive statistics for posttraumatic growth

\begin{tabular}{lccc}
\hline Measure & Mean (s.d.) & Score range (min-max) & Scale range (min-max) \\
\hline PTGI & & & Subscale mean (s.d.) \\
Total PTG (T) & $66.57(19.69)$ & $14-100$ & $0-105$ \\
Changes in self-perception (CHSP) & $28.26(10.13)$ & $0-45$ & $0-45$ \\
Changes in relations to others (CHRO) & $23.23(7.22)$ & $7-35$ & $0-35$ \\
Appreciation of life (AL) & $11.20(3.18)$ & $0-15$ & $0-15$ \\
Spiritual changes (SCH) & $6.66(2.90)$ & $0-10$ & $0-10$ \\
COPE & & & $3.14(1.13)$ \\
Focus on the problem (PROB) & $35.31(6.15)$ & $15-47$ & $3.73(1.03)$ \\
Denial (D) & $8.31(2.21)$ & $4-15$ & $4-52$ \\
Focus on/venting of emotions (EM) & $9.82(2.49)$ & $5-16$ & $4-16$ \\
Seeking emotional support (SUP) & $10.70(2.08)$ & $6-16$ & $4-16$ \\
Acceptance (A) & $14.35(2.35)$ & $9-20$ & $4-20$ \\
Religion (REL) & $9.80(3.46)$ & $4-16$ & $4-16$ \\
Humour (HUM) & $8.58(2.85)$ & $4-16$ & $4-16$ \\
Alcohol/drug use ideation (ALK) & $6.60(3.12)$ & $4-16$ & $4-16$ \\
BHI & & & $2.71(0.47)$ \\
Basic hope & $25.06(4.89)$ & $14-40$ & $2.45(0.55)$ \\
\hline
\end{tabular}

Abbreviations: BHI, Basic Hope Inventory; COPE, The Coping Orientations to Problems Experienced; PTGI, The Post-traumatic Growth Inventory.

Table 3 Correlation matrix for different outcome measures

\begin{tabular}{|c|c|c|c|c|c|c|c|c|c|}
\hline Variables & $P R O B$ & $D$ & $E M$ & SUP & $A$ & REL & HUM & $A L K$ & Basic hope \\
\hline Total PTG & $0.47 * *$ & 0.06 & 0.01 & $0.16^{*}$ & $0.32 * *$ & $0.61^{* *}$ & $0.17^{*}$ & $-0.18^{* *}$ & $0.44 * *$ \\
\hline CHSP & $0.49 * *$ & 0.09 & $0.15^{*}$ & 0.12 & $0.29 * *$ & $0.51^{* *}$ & $0.23^{* *}$ & -0.10 & $0.41^{* *}$ \\
\hline CHRO & $0.31^{* *}$ & -0.03 & $0.22^{* *}$ & $0.21^{* *}$ & $0.30^{* *}$ & $0.58^{* *}$ & 0.10 & $-0.28^{* *}$ & $0.41^{* *}$ \\
\hline
\end{tabular}

Abbreviations: A, acceptance; AL, appreciation of life; ALK, alcohol/drug use ideation; CHRO, changes in relations to others; CHSP, changes in self-perception; D, denial; EM, focus on emotions; HUM, humour; PROB, focus on the problem; REL, religion; SCH, spiritual changes; SUP, seeking emotional support; Total PTG, total posttraumatic growth.

${ }^{*} P<0.05 ;{ }^{* *} P<0.01$.

Table 4 Results of the stepwise regression analysis-total PTG

\begin{tabular}{lrrrrrrrr}
\hline Predictors & $\mathrm{B}$ & SEB & $\beta$ & $\mathrm{t}$ & $\mathrm{p}$ & \multicolumn{2}{c}{$\mathrm{Cl}$} \\
\cline { 3 - 8 } & & & & & & & & \\
& & & & & & & Lower & Upper \\
\hline REL & 2.19 & 0.31 & 0.56 & 9.16 & $0.001^{* *}$ & 1.07 & 2.16 \\
ALK & -1.83 & 0.34 & -0.38 & -6.43 & $0.001^{* *}$ & -2.52 & -1.36 \\
HUM & 2.30 & 0.41 & 0.39 & 6.00 & $0.001^{* *}$ & 0.73 & 2.05 \\
PROB & 0.74 & 0.18 & 0.19 & 3.34 & $0.001^{*}$ & 0.46 & 1.02 \\
Basic hope & 0.21 & 0.21 & 0.14 & 2.70 & $0.007^{*}$ & -0.20 & 0.57
\end{tabular}

Abbreviations: ALK, alcohol/drug use ideation; $\mathrm{Cl}$, confidence interval; HUM, humour; PROB; focus on the problem; PTG, posttraumatic growth; REL, religion; SEB, standard error of $B$. $R=0.72 ; R^{2}=0.60 ;$ Adjusted $R^{2}=0.57 ; \mathrm{F}(8.216)=37.27$.

${ }^{*} P<0.05 ; * * P<0.01$

$\left.R^{2}=0.08\right)$ was reported. All these variables jointly account for $53 \%$ of the variance of CHSP across participants $\left(R=0.73 ; R^{2}=0.53 ; \mathrm{F}\right.$ $(8.216)=30.41, P<0.001)$. For changes in relations with others, predictive role was revealed for four coping strategies only: REL $\left(\beta=0.56 ; R^{2}=0.33\right)$, ALK $\left(\beta=-0.49, R^{2}=0.08\right)$, HUM $(\beta=0.40 ;$
$\left.R^{2}=0.08\right)$, and focus on emotions $\left(\beta=-0.15 ; R^{2}=0.03\right)$. In total, these strategies account for $55 \%$ of the variance of changes in this growth aspect $\left(R=0.74 ; R^{2}=0.55, \mathrm{~F}(6.218)=45.396, P<0.001\right)$. Prevalence of increased AL may be predicted using coping strategies and basic hope, which jointly account for $43 \%$ of the variance $\left(R=0.65, R^{2}=0.43, \mathrm{~F}(6.218)=20.134, P<0.001\right)$. Predictive role is played by the following coping strategies: $\operatorname{PROB}\left(\beta=0.23, R^{2}=0.21\right)$, REL $\left(\beta=0.34, R^{2}=0.06\right)$, focus on emotions $\left(\beta=0.29, R^{2}=0.03\right)$, ALK $\left(\beta=-0.36, R^{2}=0.02\right)$, seeking emotional support $(\beta=-0.18$, $\left.R^{2}=0.02\right)$, acceptance $\left(\beta=0.14, R^{2}=0.02\right)$. Changes in this growth aspect may be also predicted using the basic hope $\left(\beta=0.34, R^{2}=0.03\right)$. Four coping strategies act as predictors of spiritual change in participants, jointly accounting for $60 \%$ of their variance $(R=0.77$, $\left.R^{2}=0.60, \mathrm{~F}(6.218)=54.90, P<0.001\right)$. These include REL $(\beta=0.68$, $\left.R^{2}=0.53\right)$, ALK $\left(\beta=-0.20, R^{2}=0.02\right), \operatorname{PROB}\left(\beta=0.25, R^{2}=0.25\right)$ and seeking emotional support $\left(\beta=-0.16, R^{2}=0.01\right)$.

\section{DISCUSSION}

The main objective of this study was to determine contribution of basic hope and coping strategies in accounting for PTG variance in individuals with traumatic long-term SCI. The obtained results 
confirmed the predictive significance of these variables for the intensity of PTG (both in general terms, as well as in its individual aspects).

Combination of predictive variables observed in the study accounts for a considerable part of PTG variance in people with long-term injury. Growth variability among participants may be predicted based on increased frequency of using strategies involving REL, HUM, focusing on the problem and in case of higher level of basic hope. Avoidance coping, on the other hand, manifested in alcohol/drug ideation will not contribute to growth in any way. These results are partially converging with other findings. ${ }^{1}$ Adverse impact of avoidance coping on producing and maintaining growth symptoms, on the other hand, complies with basic assumptions of positive growth models after trauma. For they assume indispensable personal involvement in overcoming adverse trauma outcomes and rebuilding beliefs about the world and individual's place in it. ${ }^{4}$

What is most important, however, is that study findings point to the highest contribution of REL to accounting for growth variability (in general and with regard to all growth aspects) in people living with a SCI for at least 15 years. This strategy primarily based on making meaning favours integration of traumatic event outcomes with previous cognitive patterns concerning the world and the self, which may enable occurrence and maintenance of positive changes. These results comply with other findings related to strict correlations between coping through REL and PTG. ${ }^{16}$ McMillen and Cook ${ }^{17}$ showed that coping through turning to REL shows a significant relationship with positive outcomes of SCI.

Study findings (among people with long-term SCI) point to contribution of basic hope in accounting for PTG, including two aspects thereof: self-perception and AL. The established significance of basic hope supports previous findings and confirms presumptions that the role of component beliefs is manifested in a longer perspective after traumatic event occurs. ${ }^{6}$ It is possible that, after longer period of adapting and with transformations made in perceiving the self and the world, fundamental beliefs about arrangement, good will and senses of the world encompassed in basic hope gain more meaning. As suggested in the longitudinal study by Zdankiewicz-Ścigała, ${ }^{18}$ the level of basic hope is relatively stable and undergoes no significant changes despite experiencing traumatic events or radical life changes. However, basic hope may exert different impact at specific PTG stages. ${ }^{19}$ Although study findings confirm high significance of basic hope for growth in people with a long-term injury, it would be interesting for cognitive and rehabilitation purposes to establish how its impact changes in different periods of growth and during maintenance of its specific manifestations. What is more, obtained results showed contribution of basic hope in accounting for positive CHSP and increased AL. This complies with the adaptive function ascribed to hope, especially reflected in case of an irreversible loss when an individual is forced to choose and accept new life alternatives and to search for new, previously unnoticed qualities inside themselves that would help cope with emerged circumstances. 5,20

Given the severity of positive changes that make up the PTG should be noted that participants reported the biggest changes in AL, which also confirms findings of Chun and Lee, ${ }^{2,21}$ who via narrative interviews found that positive changes are most broadly manifested in appreciation of every moment, little things and everyday reality. The smallest positive CHSP, on the other hand, are not converging with other studies; Pollard and Kennedy, who found considerable degree of positive changes manifested in AL, concluded that highest personal strength was observed in participants after 10 years since SCI onset. ${ }^{1}$ Similarly, Kalpakjian et al. ${ }^{3}$ found that positive changes are manifested most strongly in establishing more intimacy with others and discovering that one is stronger than actually expected.

On the basis of these results, the following conclusions can be formulated:

1. People with long-term SCI experience PTG, which is most strongly manifested in a greater appreciation of everyday life.

2. Coping strategies (especially REL) and basic hope have a significant role in explaining the variance of PTG in this group of people with disabilities.

These results are useful not only in cognitive but also in therapeutic and rehabilitation terms. Subjective perception of positive changes in people with SCI and establishing the determinants of these changes identified in the study may be important for broadening the scope of possibilities of intervention.

Although study findings are interesting indeed, they have some limitations. First, the group of participants is not representative. People enrolled in the study intentionally included only those active in various life areas. They were assumed to stand a higher chance of identifying PTG, which complies with theoretical assumptions of growth models stating that growth is not universal and occurs in some individuals only. Second, explanation of growth variability in people with a long-term spinal injury presented here should be treated as an initial diagnosis. Longitudinal studies in this respect are required to determine the long-term and supposedly variable impact of individual coping strategies and basic hope. Third, the study fails to solve the fundamental question: when do participants observe first manifestations of growth and for how long they persist. Fourth, PTG analysis is based on results of quantitative research. In the context of studies by other authors, one might expect that qualitative analyses would provide additional, unique information about growth over a long period of adapting to living with an acquired damage. ${ }^{22}$

Summing up, PTG in people with SCI has been the focus of an increasing body of research. Numerous issues concerning the very essence of growth, its stages, maintaining the degree and scope of positive changes, as well as factors accounting for their variability, still require multi-dimensional explanations. These will surely consider basic hope. Detailed identification of their functions in PTG occurrence and adaptation processes will provide valuable expertise in the field of rehabilitation and treatment of people after traumatic SCI.

\section{DATA ARCHIVING}

There were no data to deposit.

\section{CONFLICT OF INTEREST}

The author declares no conflict of interest.

1 Pollard C, Kennedy P. A longitudinal analysis of emotional impact, coping strategies and post-traumatic psychological growth following spinal cord injury: a 10-year review. Br J Health Psychol 2007; 12: 347-362.

2 Chun S, Lee $Y$. The experience of posttraumatic growth for people with spinal cord injury. Qual Health Res 2008; 18: 877-890.

3 Kalpakjian CZ, McCullumsmith CB, Fann JR, Richards JS, Stoelb BL, Heinemann AW et al. Post-traumatic growth following spinal cord injury. J Spinal Cord Med 2014; 37: 218-225.

4 Tedeschi RG, Calhoun LG. Posttraumatic growth: conceptual foundations and empirical evidence. Psychol Inq 2004; 15: 1-8.

5 Trzebiński J, Zięba M. Basic hope as a world-view: an outline of a concept. Polish Psychol Bull 2004; 35: 173-182. 
6 Zięba M, Czarnecka-van Luijken J, Wawrzyniak M. Nadzieja podstawowa i wzrost potraumatyczny [Basic hope and posttraumatic growth]. Studia Psychologiczne [Psychol Stud] 2010; 49: 109-121.

7 Livneh H, Martz E. Coping strategies and resources as predictors of psychosocial adaptation among people with spinal cord injury. Rehabil Psychol 2014; 59: 329-339.

8 Kennedy P, Lude P, Elfström ML, Smithson E. Cognitive appraisals, coping and quality of life outcomes: a multi-centre study of spinal cord injury rehabilitation. Spinal Cord 2010; 48: 762-769.

9 Chevalier Z, Kennedy P, Sherlock O. Spinal cord injury, coping and psychological adjustment: a literature review. Spinal Cord 2009; 47: 778-782.

10 Elfström ML, Ryden A, Kreuter M, Persson L-O, Sullivan M. Linkages between coping and psychological outcome in the spinal cord lesioned: development of SCL-related measures. Spinal Cord 2002; 40: 23-29.

11 Elfström ML, Kreuter M, Ryden A, Persson L-O, Sullivan M. Effects of coping on psychological outcome when controlling for background variables: a study of traumatically spinal cord lesioned persons. Spinal Cord 2002; 40: 408-415.

12 Kennedy P, Lude P, Elfström ML, Smithson E. Appraisals, coping and adjustment pre and post SCI rehabilitation: a 2-year follow-up study. Spinal Cord 2012; 50: $112-118$.

13 Ogińska-Bulik N, Juczyński Z. Rozwój potraumatyczny—charakterystyka i pomiar. [Posttraumatic growth—characteristics and measurement]. Psychiatria [Psychiatry] 2010; 4: 129-142.
14 Wrześniewski K. Pomiar radzenia ze stresem—wybrane zagadnienia. [Measurement of coping with stress-selected issues]. Promocja Zdrowia. Nauki Społeczne i Medycyna [Health Promot Soc Sci Med] 1996; 8-9: 34-46.

15 Trzebiński J, Zięba M. Nadzieja, strata i rozwój. [Hope, loss and development]. Psychologia Jakości Życia [Psychol Qual Life] 2003; 1: 5-33.

16 Geber MM, Boals A, Schuettler D. The unique contributions of positive and negative religious coping to posttraumatic growth and PSD. Psycholog Relig Spirituality 2011; 3: 298-307.

17 McMillen JC, Cook CL. The positive by-products of spinal cord injury and their correlates. Rehabil Psychol 2003; 48: 77-85.

18 Zdankiewicz-Ścigała E. Nadzieja podstawowa jako moderator procesu adaptacji po traumie (Basic hope as a moderator of adaptation after trauma). In: Strelau J, Zawadzki B, Kaczmarek M (eds). Konsekwencje Psychiczne Traumy: Uwarunkowania i Terapia. (Psychological Sequelae of Trauma: Conditions and Therapy) Wydawnictwo Naukowe Scholar: Warszawa, Poland, 2009, pp 128-149.

19 Parashar D. The trajectory of hope: pathways to find meaning and reconstructing the self after a spinal cord injury. Spinal Cord 2014; 53: 565-568.

20 Lohne V, Severinsson E. The power of hope: patients' experiences of hope a year after acute spinal cord injury. J Clin Nurs 2006; 15: 315-323.

21 Chun S, Lee Y. The role of leisure in the experience of posttraumatic growth for people with spinal cord injury. J Leis Res 2010; 42: 393-415.

22 Kennedy $P$, Lude P, Elfström ML, Cox A. Perceptions of gain following spinal cord injury: a qualitative analysis. Top Spinal Cord Inj Rehabil 2013; 19: 202-210. 